\title{
Concerns and expectations of students participating in study abroad programs: Blogging to reveal the dynamic student voice
}

Robin Bell (r.bell@worc.ac.uk)

Journal of Research in International Education (Accepted August 2016)

\begin{abstract}
Study abroad programmes (SAP) have become increasingly popular with university students and within academia. They are often seen as an experiential opportunity to expand student learning and development, including increases in global, international, and intercultural competences. However, despite the increasing popularity of and participation in study abroad programmes, many student concerns and uncertainties remain. This research investigates initial pre-departure concerns and apprehensions of students undertaking a one-semester study abroad programme and uses these as context for an examination of violated expectations of students during their programme. The research uses interpretative phenomenological analysis to interpret data collected from regularly-updated blogs composed by students throughout their SAP experience. The process of using blogs to collect data is less formalised than many other approaches of interpretative phenomenological analysis, enabling 'in the moment' feedback during the SAP and lending greater depth to the understanding of student perceptions.
\end{abstract}

\section{Key Words}

Study Aboard, Erasmus, Student Expectations, Student Blogs 


\section{Introduction}

Study abroad programmes (SAPs) are an experiential opportunity to expand student learning and development (Paige \& Fry, 2010). SAPs can be defined as "all educational programmes that take place outside the geographical boundaries of the country of origin" (Kitsantas, 2004). As globalization has internationalized many processes and operations, education is no exception; as a result, universities are increasingly promoting international study (Ahn, 2014). The potential benefits of participation in SAPs include increased appreciation of global issues and intercultural awareness (Douglas \& Jones-Rikkers, 2001), greater sensitivity to new and different cultures (Wright \& Clarke, 2010), understanding of global interdependence (Sutton and Rubin, 2004), and increased intercultural communication skills (Wright \& Clarke, 2010). SAPs have been shown to have a broad and long-lasting impact on students' lives (Paige et al, 2009), increasing self-confidence, leadership skills and problem-solving skills, and fostering open-mindedness (Ingraham \& Peterson, 2004; Black \& Duhon, 2006; Sachau et al, 2010). SAPs may also positively impact the early stages of career development (Potts, 2015), giving students a competitive edge when seeking employment (Peacock 2005) and preparing students to work in a global and multicultural environment (Mor-Barak, 2011).

In an increasingly global environment, the ability to communicate effectively with those of different cultures is becoming a vital requisite in many fields including marketing (Jones, 2003), engineering (Klahr and Ratti, 2000), and business (Tarrant, 2010; Hallows et al., 2011). International and more diverse workplaces demand employees with international and intercultural skills (Hallows et al, 2011). As such, cross-cultural skills are required both by organisations and by students competing in the employment market (Williams 2005). Indeed, the development of attractive and high-quality exchange programs is often seen as an aid to university student recruitment (European Commission [EC], 2013). The number of American and European college students participating in SAPs has been increasing (Bandyopadhyay and Bandyopadhyay, 2015; EC, 2013). Nevertheless, only 10 percent of American or European Union (EU) university undergraduates currently undertake SAPs (Redden 2014; EC, 2013; European Union, 2013). The small percentage of students participating in SAPs, despite increased focus and support, suggests that there is room for further investigation of factors that concern students before and during their study abroad. This research draws from student 
blogs to investigate student concerns and expectations before and during their SAP experience.

\section{Study Abroad}

\section{The Choice to Study Abroad}

To explore the perceived concerns and expectations that create barriers to studying abroad, it is useful to examine the theoretical frameworks that influence a student's choice to study abroad. Human capital theory, which suggests that students can improve their individual capacities through investment in education, is argued to influence students' educational choices (Salisbury et al, 2009). Supporting this is Thirolf's (2014) study that found that many students forgo SAPs because they would rather focus their energy on experiences that they believe will enhance their résumés with concrete outcomes in order to secure employment, meaning students may perceive workplace experience and internships as more valuable and capital-building than study-abroad experiences.

Perna (2006) argues that students make decisions regarding their higher education by weighing expected benefits and costs, which is influenced by, inter alia, their values and beliefs, and Salisbury et al (2009) suggest that this 'student-choice construct' can be applied to study abroad choices. These choices are also subject to cultural and social capital levels, which would indicate that access to information, resources, and interaction with other participating individuals may influence student choices.

Potential barriers to participation can include cost (Foster, 2014), difficulties with transferring credits between universities, delaying graduation (Shaftel et al, 2007), work, academic scheduling, family, and financial considerations (Lenz and Wister, 2008). Interestingly, is has been argued that students who benefit from Erasmus schemes (student exchange programme that provides scholarships for European Union students to study abroad) perceive similar barriers to study abroad as do their non-Erasmus European student counterparts (Beerkens et al, 2016), suggesting that reducing financial barriers may not in itself increase student participation in SAPs. 


\section{Study Abroad Programme Concerns and Expectations}

Research has suggested that addressing the concerns of students can play an important role in influencing their decision to study abroad (Maringe \& Carter, 2007). Findlay et al (2006) consider the significance of financial factors in student decision-making, and Klahr and Ratti (2000) identify barriers perceived by students to engaging in SAPs, including academic prerequisites and qualifications for the foreign university that students either do not understand or do not meet, differences in academic year structures, a lack of foreign language skills, information on local living conditions, and knowledge about local accommodation. Other perceived barriers described in the literature include a lack of support from home university faculty and staff, particularly from academic advisors who could help students understand how an SAP could fit into their academic journey, and a lack of information about studying abroad (Matthews et al, 1998). The perception of barriers varies among individual students; while learning a foreign language may intimidate some students, for instance, it may motivate others (Nilsson 2014). For some students, the concerns emanating from perceived barriers may be overcome, or at least reduced, by the provision of appropriate information, guidance, and preparation, which requires planning on the part of universities (Lillyman \& Bennett, 2014).

Engle and Engle (2003) noted that success in university SAPs often was measured by how many students studied abroad rather than on the quality of the SAP and its contribution to students' development. They developed a system for categorizing SAPs on the basis of the level of students' immersion in the host culture. This approach allows student needs to be matched to appropriate SAPs in decision-making, as well as appropriate preparation beforehand. Such preparation can help students to have more realistic expectations, leading to a more positive experience (McLeod and Wainwright 2009). McLeod and Wainwright (2009), using post-SAP focus group data, found that expectations, both met and unmet, were significantly related to how students viewed their SAP experiences.

\section{Expectation Violation Theory}

Expectation Violation Theory (EVT) (Burgoon, 1978) was developed to explain how people respond to unexpected communication and will be used in this study as a theoretical framework to understand students' SAP experience. EVT originally focused on non-verbal behaviour, but has since been extended to include verbal behaviours. Expectation can be 
defined as "an enduring pattern of anticipated behaviour that may be either generalized or person specific" (Burgoon \& Walthers, 1990, p. 235). Using this theoretical framework, expectations derive from communicator, relationship, and contextual characteristics (cultural and situational). Norms and values are thus based on the social and cultural environment as well as on past experiences. Individuals expect that others will follow the same set of norms and values (Burgoon and Walthers, 1990). However, norms, rules, and expectations vary between cultures, and are easy to violate due to a lack of understanding (Burgoon, 1995). Human interaction is driven by learned expectations, and variations thereto may elicit reaction. The greater the negative variation with an interaction or experience, the greater can be the potential for doubt, uncertainty, anxiety a disillusionment. Similarly, positive interactions relative to expectations lead to more favourable outcomes (Burgoon et al, 1995). Analysing data on SAPs through the lens of EVT can offer an informative background to students' perceptions and experiences during a SAP in a 'foreign' environment. Differences in local customs, teaching, and communication styles hold the potential to create dissatisfaction and uncertainty.

\section{Blogging to Reveal the Student Voice}

Research in the use of social media and blogs in education is relatively new, given that the technology is also in its early stages. Blogs and other forms of social media have been argued to be easily-accessible, user-friendly means of networking, collaborating, communicating, and gathering information (Schroeder et al, 2010). Blogs are increasingly used in higher education, allowing for greater interaction among and between students and instructors, and creating real-time notifications of information and feedback, as well as a chronological record of interactions (Yueh et al, 2014; Bausch et al, 2002). The sense of control over the structure of an individual blog has been found to create an atmosphere of comfort, facilitating reflection (Karger and Quan, 2004) and thus supporting social and individual learning (Lin et al., 2006). Tolmie and Boyle (2000) and Pena-Shaff et al (2005) suggested that online forums such as blogs give individuals a sense of ownership, increasing the likelihood of successful communication between students and faculty and/or peers and reducing anxiety about participating in online communication. 
Blogs have been found to elicit an affective response in students, resulting in the sharing of personal information (Leslie \& Murphy, 2008). Students may prefer to post about their lives rather than share factual information (Leslie \& Murphy, 2008). A social need for personal connections may motivate the high level of self-disclosure seen in blogs (Ma et al, 2006; Leslie \& Murphy, 2008). Kim (2008) applied Lawler's (1973) theory that motivation is influenced by the expectation of outcomes to argue that individuals are motivated to increase their participation in blogging by seeing feedback to their blog posts.

\section{The Research: Aim and Methodology}

The continual review and assessment of SAPs ensures students' learning and development needs are met, thus maintaining the credibility of programs (Williams, 2005; McLeod \& Wainwright, 2009). In line with recommendations by Engle and Engle (2003) and McLeod and Wainwright (2009), this research sought to develop an understanding of students' concerns and expectations prior to and while taking part in a SAP, to add depth to the literature on developing preparations and ongoing support which will help students realize the benefits of studying abroad (Behrnd \& Porzelt 2012).

Qualitative data were collected from student-authored blogs narrating their individual experiences before, during, and after their SAP. Sixteen students preparing for a onesemester SAP volunteered to participate, agreeing to write six blog posts throughout their experience on directed topics to enable reflection and development. The students in the study were European and came from the same home university in the United Kingdom. Because they had access to Erasmus scheme funding, students had a stipend to cover their living costs while abroad and paid no additional tuition fees. The SAP placements were all voluntary and provided transferable credits. Students studied abroad at six different institutions. The SAP placements were all undertaken within Western Europe, in non-English speaking countries, while academic instruction was in English. Students chose their modules during the SAP based on their course of study, so there was no fixed 'programme' at any of the universities for international students and all students mixed into regular classes with peers on similar courses of study. While some of the students in the study went to the same foreign university, they were not in the same programmes of study and thus were in different modules during the SAP. 
Students were asked by the researcher (a faculty member charged with providing academic advice for SAP students, but who was not the students' instructor) to write an initial blog post before departing for their SAP, detailing their concerns and expectations regarding their time studying abroad. The students were encouraged to write at least four posts throughout their SAP experience to provide an ongoing narrative of their experiences. Students were asked to reflect, upon or just before their return, and then blog on their original concerns and expectations and their overall experiences in light of these. The timeline of the blog posts was left to the individual students, allowing students to write whenever they were 'in the moment.'

Students were assured that their blog posts would remain anonymous for the purpose of the research and were given suggestions of free blog-hosting websites. They were allowed to choose whether to share their blogs with friends and family. The narratives collected from the blogs were collated and interpretative phenomenological analysis (IPA) was used to analyse the findings. Blogs were an ideal data source for this analysis; allowing the subjects the opportunity to detail their views and thoughts freely in their own time, rather than in a more formal, semi-structured 'after the event' interview setting that has typically been used for IPA (Braun and Clarke, 2013; Smith, 1995). Linked to the fact that the goal of this study was to create a real-time archive of affective responses to the study-abroad process, the use of blogs allowed for ongoing data points and reduced the retrieval and memory problems associated with ex-post interviews (Tourangeau, 1984).

In line with arguments that blogs fulfil a need for social connection with others and elicit sharing of personal information (Ma et al, 2006; Leslie and Murphy, 2008), all of the students eschewed anonymity and chose to share their blog entries. Many posted links to their blog entries to social media outlets (e.g. Facebook) and elicited comments and 'likes' in response to their posts. All students composed more blog entries than were requested by the researchers. In addition, students embraced their blogs and the concept of their being read by others; nearly all of the students began them blogs with introductions of themselves for their readers. 


\section{Findings}

\section{Initial postings: Pre-departure expectations and concerns}

The first blog posts by the students provided the lens through which the participants' later postings could be viewed, thus providing insights into their pre-departure assumptions and expectations (Braun and Clarke, 2013). This lens allowed the researchers to better interpret students' reactions to their SAP experiences. Postings before departure focused on hopes and expectations, and concerns and anxieties. Students expressed optimism and excitement at the concept of moving away from their home country (all for the first time) and immersing themselves in a wholly new culture. Responses indicated that students believed they would return from their experience more cultured and worldly, often with greater fluency in a foreign language. The use of emoticons to convey hope and happiness was strong in these initial posts. Students focused on how the experience would shape and change them in a positive way. For example:

"dreams of spur-of-the-moment train rides ... getting lost in the cobblestones with nothing to do but absorb everything."

"It's a big step towards independence"

“ $t_{\$}$ New, amazing city, new experience, have a mini fresh start."

"I am sure it's a life changing experience and that I will definitely regret if I won't take this opportunity, so off we go!"

Students appeared cognizant that they were being offered something special in the SAP; they judged the opportunity to be rare and special. Students seemed confident that their SAP experience would not be a great challenge and felt they were prepared to live in another culture. Initial blog posts held predictions of future success in another culture and often 'invited' the reader to follow their blog postings. The language was light and peppered with positive emotions and an aura of cultural invincibility that they felt could benefit or impress readers. 
Despite this optimism about the 'big picture', analysis indicated pre-departure concerns intermixed with enthusiasm. Students were both worried and excited about making new friends. This seemed to be an unknown that was not fully grasped:

"No exchange programme experience can be fun without people with who[m] you can hang out and spend time together ... really looking forward to meeting new people with who[m] I can share my experiences and discoveries."

Loneliness and isolation during SAPs has been highlighted by several authors, including Sawir et al (2008), Nilsson (2014), and Robertson et al (2000). However, while previous studies have often focused on both distance from loved ones and making new friends, only one student expressed concern about being far from her family. Indeed, this study's blogs may help explain the shift towards being more concerned about new friends. Increased internet access, enabling free or inexpensive communication with friends and family, may mitigate these concerns ex ante.

Logistically, students expressed concerns about luggage size, packing for a semester abroad, and navigating transportation stations by themselves to arrive at their new home. While this matter is not often highlighted in the SAP literature, these pre-departure blog posts may have captured concerns long forgotten after the SAP experience. In contrast with previous studies (e.g. Luethge, 2004), concerns about money stemmed from how they would access their funds from foreign banks, and credit card acceptance. The availability of Erasmus funding likely mitigated most money concerns. Most students at the time of the first blog had not secured housing and accommodations were a primary concern. The host universities provided students with information on housing and suggested companies ahead of their arrival, but ultimately the students were responsible for securing their own place to live for the semester. Students worried about finding a permanent place to live and the cost of rent, as well as their future roommates and the quality of the accommodation. The perception of a lack of suitable or affordable accommodation, and unknowns regarding the host country's living conditions, are highlighted in the literature as potential barriers to the undertaking of SAPs (e.g. Klahr \& Ratti, 2000). For example:

"I am really freaked out about the place I am going to stay for a semester." 
Academically, students wondered how they would fit into their new classes, and while many were excited to learn a new language, one student was concerned with being understood in her new country. Others presumed English would be spoken widely. Concern was expressed with how their classes would be taught and their ability to adapt to a new educational style.

"How will the lectures be? What about teachers? Will I understand? Oh no ! Assignments !?”

\section{During the SAP: Violated Expectations}

The tone of the blog postings changed during the students' SAP experience. They reported a number of frustrations or violated expectations, both about their domiciles and their education.

\section{Violated Social Expectations}

Data collected indicated a perceived lack of cultural immersion compared to original expectations. While courses were taught in English, during groupwork domestic students would often revert to their own language, which continued after class, resulting in the SAP students feeling disengaged and like outsiders. Students appeared more focused on the 'international experience' rather than on integrating with the existing culture. Data reflected friendship circles mainly consisting of international students. The tone of postings indicated pride in making multicultural friendship bases with others who were not from the host country, be it on study-abroad programmes or who were expatriates living in the country long-term, and few comments were made about friendships with domestic students. Students wrote that they related better to other international students, reducing some of the opportunities for experiential learning that can come from cultural immersion (Jones, 2003; Bandyopadhyay and Bandyopadhyay, 2015). A feeling of isolation or time spent largely with other expatriates can reduce the potential benefits that the SAPs can offer (Doyle et al., 2010). Students reported with pride their preference for friendships with other SAP students, who came from many different countries, seeing these friendships as a mark of their burgeoning worldliness, and often listing the number or names of countries from which their new friends came. Comments about friendships with domestic students were often part of another 
narrative rather than the topic of the post. It should be noted that the shared nature of the blogs may have impacted this, as students may have wanted to focus on the more romantic and 'international' aspects of their SAP for their readers.

While students had focused, pre-departure, on the adventure of living in a new culture, they may have found the day-to-day nature of the new domicile disappointing. Students bemoaned slow internet connections and technological differences, soliciting advice from other SAP students because they felt it was rude to ask a local. This theme continued when students expressed disillusionment with their new neighbourhoods. While some reported that they "could not believe it each day when I looked out the door" in reference to the idyllic scenery, others were aghast at the homeless population, the litter in locations previously believed to be iconic, and level of customer service:

"Basically all these things are slower than in the UK. Additionally you may have to push to get things done. Get used to waiting."

Central to Expectation Violation Theory is the role that existing expectations play (Burgoon \& Hubbard, 2005). Students responded to violated expectations by associating with other international students. The data suggested that students felt they could empathize regarding violated expectations of the SAP. While Ruben and Kealey's (1979) "U-curve" culture shock cycle argued that feelings of isolation and alienation are followed by a retreat to the home culture, the path these students followed may be more closely aligned with the work of Brein and David (1971), who argued that the cultural adjustment process is aided by developing interpersonal relationships based on mutual understanding. The SAPs were a semester long or "long-term" (Carley, Stuart \& Dailey, 2011)), and the data indicates that effective cultural immersion may take longer than this, though a semester does allow for meaningful crosscultural interaction.

Another violated expectation noted in blog postings was disappointment in not developing foreign language skills, often one of the main incentives for students to participate in SAPS (Nilsson 2014). The initial violated expectations regarding lifestyle and customer service may have led to the preference for associating with other international students, which may have exacerbated this problem. In addition, English language was reported to be often used in casual conversation with other international students since it was spoken by everyone, often 
as a second language and often more fluently than the host-country language. Wright and Schartner (2013) similarly found that frustration with levels of social interaction during an SAP coincided with students' reluctance to interact with the host country culture.

\section{Violated academic expectations}

It was clear that students felt conflicted about their struggles with different academic systems, and at different times referred to these systems as both "refreshing" and "impossible". Students admitted that there was an adjustment needed to different teaching and learning styles at their new institution. Early postings celebrated students' ability to adapt. As the semester progressed, students may have felt at a loss to explain how the academic systems were different, and they would reconcile the new teaching style by categorizing it as "experience-based" or "theory-based". As the semester moved towards exams, discomfort with these differences was emphasized.

A different communication style with faculty than they were used to made students uncomfortable. Confusion was expressed at needing appointments for face-to-face meetings rather than communicating primarily by email. Postings reflected anxiety when faculty did not immediately respond to email messages, and discomfort with in-person meetings, with tones reflecting that these universities were 'behind' their home institution. SAPs can help to improve problem-solving skills, the ability to cope with the unfamiliar, and open-mindedness (Ingraham \& Peterson, 2004; Black \& Duhon, 2006). Learning to adapt to institutional differences can be argued to be a long-term benefit of SAPs. In the short term, however, students clearly felt their expectations of faculty to be violated.

The language style changed when frustrations were at their highest with the new teaching style: close to examination time. Students no longer spoke as an individual; they now formed part of a collective with fellow SAP students:

"Most of us are likely to fail."

"Recently we have often found parts of the exchange program to have been pretty unmanageable." 
A tone of abandonment was clear in many later postings. Students expressed indignation that they had not been given a fair chance to pass the modules and had experienced substandard teaching. This occurred for at least three of the different universities students attended. Students complained of cancelled lectures, being unprepared for examinations, inadequate teaching, and faculty apathy, all of which they felt would be to blame if they did not pass their examinations. These examples provide important insights into how initial worries and concerns can play out, and how unmet expectations can result in dissatisfaction and disappointment.

The negativity expressed towards the education system may also be linked to the students' lack of connection to the university. While friendships at the university level are argued to influence academic performance and satisfaction (Ashwin, 2003), so too does the level of connection with the university community (Pittman \& Richmond, 2008). The focus on connections with other international students may undermine the university connection necessary to realize the benefits of a new learning style.

\section{Discussion and Conclusions}

This research sought to develop an understanding of student concerns and apprehensions prior to a study abroad programme, and to follow their experiences in order to gain understanding of what expectations were violated. It was hoped that the informal use of blogs would capture a rich source of 'in the moment' detail that could otherwise be lost over time, but that would be useful in future SAP preparation. The greatest source of pre-departure anxiety was accommodation. Once abroad, most students felt their expectations were violated in some way, often with respect to their new domicile, including technology access and customer service. Overall, a greater emphasis was placed on living an 'international' lifestyle rather than integrating into the host country's culture. Academically, students experienced most anxiety through the different communication, teaching, and assessment styles and reacted often by blaming the hosts. While these blogs offer only a snapshot of the student experience, they provide a useful perspective to ongoing SAP research.

Doyle et al. (2010) concluded that ongoing support for students, social support abroad and help in developing intercultural competence through interaction and relationships with others in the host country (i.e. immersion) will all benefit students and promote the uptake 
of placements abroad. Reviewing and learning from research such as this can enable universities to prepare students and impart realistic expectations. Altered expectations may then mitigate some of the affective responses of students to their new home, resulting in a more enriching SAP experience. SAP student blogs may serve as a record of experiences highlighting adjustments to accommodation, cultural, educational and communication differences. Shao and Crook (2015) found group blogs to be beneficial among student cohorts studying abroad. These blogs that address major issues and concerns could aid prospective SAP students and be preserved as an archive for future student and faculty reference.

Analysis of the blogs indicated that, for many students, entering the unknown can be a stressful experience. Despite this study's analytic emphasis on violated expectations, postings were positive overall, indicating benefits from the experience, in line with previous research (e.g. Paige et al., 2009). The information in this study can be used to re-evaluate how universities provide pre- and post-departure assistance. The purpose of this research is not to encourage the impossible extinguishment of the romantic hopes associated with SAPs, but rather to provide insight on which of these can result in problems when students study abroad.

It is worth noting that in addition to the natural variation to be found in the concerns and expectations between individual students from any given educational establishment, the outcome of the experience relative to the expectancy will be coloured by the students' experiences at their home university. Additionally, the use of blogs as a data source for IPA is a new phenomenon and its full range of limitations is yet to be discovered, which may include social desirability bias, that is, an inherent bias towards what an individual believes to be a socially desirable response (Maccoby \& Maccoby, 1954). In addition, blogs may not be an appropriate research tool for all demographics, with the students in the study having grown up in the UK with computer and internet access. While blogs have been shown to give students a sense of control and ownership, more research into the validity of the data verses the interviews traditionally used for IPA would bring more depth and perspective to the topic. 


\section{References}

Ahn, S. E. (2014). A good learning opportunity, but is it for me? A study of Swedish students' attitudes towards exchange studies in higher education. Journal of Research in International Education, 13(2), 106-118.

Ashwin, P. (2003). Peer support: Relations between the context, process and outcomes for the students who are supported. Instructional Science, 31(3), 159-173.

Bandyopadhyay, S., \& Bandyopadhyay, K. (2015). Factors influencing student participation in college study abroad programs. Journal of International Education Research, 11(2), 87-94.

Bausch, P., Haughey, M., \& Hourihan, M. (2002). We blog: Publishing online with weblogs. Indianapolis, IN: Wiley Publishing.

Beerkens, M., Souto-Otero, M., de Wit, H., \& Huisman, J. (2016). Similar students and different countries? An analysis of the barriers and drivers for Erasmus participation in seven countries. Journal of Studies in International Education, 20(2), 184-204.

Behrnd, V., \& Porzelt, S. (2012). Intercultural competence and training outcomes of students with experiences abroad. International Journal of Intercultural Relations, 36(2), 213-223.

Black, H. T., \& Duhon, D. L. (2006). Assessing the impact of business study abroad programs on cultural awareness and personal development. Journal of Education for Business, 81(3), 140-144.

Brein, M., \& David, K. H. (1971). Intercultural communication and the adjustment of the Sojourner. Psychological Bulletin, 76(3), 215.

Braun, V., \& Clarke, V. (2013). Successful qualitative research: A practical guide for beginners. London, UK: Sage.

Burgoon, J. K. (1978). A communication model of personal space violations: explication and an initial test. Human Communication Research, 4(2), 129-142.

Burgoon, J. K. (1995). Cross-cultural and intercultural applications of expectancy violations theory. In R. Wiseman (Ed.), Intercultural communication theory (pp. 194-214). Thousand Oaks, CA: Sage.

Burgoon, J. K., \& Hubbard, A. E. (2005). Cross-cultural and intercultural applications of expectancy violations theory and interaction adaptation theory. In W.B. Gudykunst (Ed.), Theorizing about intercultural communication (pp. 149-171). London, UK: Sage.

Burgoon, J. K., Stern, L. A., \& Dillman, L. (1995). Interpersonal adaptation: Dyadic interaction patterns. Cambridge, UK: Cambridge University Press. 
Burgoon, J. K., \& Walther, J. B. (1990). Nonverbal expectancies and the evaluative consequences of violations. Human Communication Research, 17(2), 232-265.

Carley, S., Stuart, R., \& Dailey, M. (2011). Short term study abroad: An exploratory view of business students outcomes. Journal of Management Policy and Practice, 51(39), 44-53.

Douglas, C., \& Jones-Rikkers, C. G. (2001). Study abroad programs and American student worldmindedness. Journal of Teaching in International Business, 13(1), 55-66.

Doyle, S., Gendall, P., Meyer, L. H., Hoek, J., Tait, C., McKenzie, L., \& Loorparg, A. (2010). An investigation of factors associated with student participation in study abroad. Journal of Studies in International Education, 14(5), 471-490.

Engle, L., \& Engle, J. (2003). Study abroad levels: toward a classification of program types. Frontiers: The Interdisciplinary Journal of Study Abroad, 9, 1-20.

European Union. (2013). Number of Erasmus students tops 3 million (No. IP/13/657). Brussels: European Union. Retrieved from http://europa.eu/rapid/press-release IP-13$\underline{657 \text { en.htm }}$

European Commission. (2013). European higher education in the world (COM (2013) 499 final). Communication from the Commission to the European Parliament, the Council, the European Economic and Social Committee and the Committee of the Regions. Retrieved from: http://ec.europa.eu/transparency/regdoc/rep/1/2013/EN/1-2013-499-EN-F1-1.Pdf

Findlay, A., King, R., Stam, A., \& Ruiz-Gelices, E. (2006). Ever reluctant Europeans: The changing geographies of UK students studying and working abroad. European Urban and Regional Studies, 13(4), 291-318.

Foster, M. (2014). Student destination choices in higher education: Exploring attitudes of Brazilian students to study in the United Kingdom. Journal of Research in International Education, 13(2), 149-162.

Hallows, K., Porter Wolf, P, \& Marks, M. (2011). Short-term study abroad: a transformational approach to global business education. Journal of International Education in Business, 4(2), 88-111.

Ingraham, E., \& Peterson, D. L. (2004). Assessing the impact of study abroad on student learning at Michigan State University. Frontiers: The Interdisciplinary Journal of Study Abroad, 10, 83-100.

Jones, W. H. (2003). Over the wall: Experiences with multicultural literacy. Journal of Marketing Education, 25(3), 231-240. 
Karger, D. R., \& Quan, D. (2004). What would it mean to blog on the semantic web? In S.A. Mcllraith, D. Plexousakis, \& F. van Harmelen (Eds) The Semantic Web-ISWC 2004 (pp. 214228). Berlin Heidelberg: Springer.

Kim, H. N. (2008). The phenomenon of blogs and theoretical model of blog use in educational contexts. Computers \& Education, 51(3), 1342-1352.

Kitsantas, A. (2004). Studying abroad: The role of college students' goals on the development of cross-cultural skills and global understanding. College Student Journal, 38(3), 441-452.

Klahr, S. C., \& Ratti, U. (2000). Increasing engineering student participation in study abroad: A study of U.S. and European programs. Journal of Studies in International Education, 4(1), 79-102.

Lawler III, E. E. (1973). Motivation in work organizations. Michigan, US: Brooks/Cole Publishing Company.

Lenz, W., \& Wister, J. (2008). Short-term study abroad with long-term benefits. International Education, 17(3), 84-87.

Leslie, P. H., \& Murphy, E. (2008). Post-secondary students' purposes for blogging. The International Review of Research in Open and Distributed Learning, 9(3), 1-17.

Lillyman, S., \& Bennett, C. (2014). Providing a positive learning experience for international students studying at UK universities: A literature review. Journal of Research in International Education, 13(1), 63-75.

Lin, W. J., Liu, Y. L., Kakusho, K., Yueh, H. P., Murakami, M., \& Minoh, M. (2006). Blog as a tool to develop e-learning experience in an international distance course. Sixth IEEE International Conference on Advanced Learning Technologies, Kerkrade, The Netherlands (pp. 290-292).

Luethge, D. (2004). Perceived risk and risk reduction strategies in study abroad programs. Journal of Teaching in International Business. 15(4), 23-45

Ma, W., Li, P., \& Clark, T. (2006). Examining the cognitive style effects on the acceptance of online community weblog systems. Paper presented at the 2006 Proceedings of the 38th Annual Hawaii International Conference on System Sciences.

Maccoby, E. E., \& Maccoby, N. (1954). The interview: A tool of social science. In G. Lindzey (Ed.), Handbook of social psychology: Vol. 1. Theory and method (pp. 449-487). Reading, MA: Addison Wesley.

Maringe, F. \& Carter, S. (2007). International students' motivations for studying in UK HE. International Journal of Educational Management, 21(6), 459-475. 
Matthews, P. R., Hameister, B. G., \& Hosley, N. S. (1998). Attitudes of college students toward study abroad: Implications for disability service providers. Journal of Postsecondary Education and Disability, 13(2), 67-77.

McLeod, M., \& Wainwright, P. (2009). Researching the study abroad experience. Journal of Studies in International Education, 13(1), 66-71.

Mor-Barak, M. E. (2011). Managing diversity: Toward a globally inclusive workplace. Los Angeles, CA: Sage Publications.

Nilsson, P. A. (2014). Great expectations among outbound Swedish exchange students - A case from Umeå University. Presented at the 2014-2020: A New Challenge for Coordinators of the European Projects, Prague.

Paige, R. M., \& Fry, G. W. (2010). Beyond immediate impact: Study abroad for global engagement (Report Submitted to the Title VI: International Research and Studies Program, U.S. Department of Education). Development College of Education and Human Development, University of Minnesota.

Paige, R. M., Fry, G. W., Stallman, E. M., Josic, J., \& Jon, J. E. (2009). Study abroad for global engagement: The long-term impact of mobility experiences. Intercultural Education, 20, 2944.

Peacock, J. (2005). Corporate recruiters' perceived value of study abroad and international travel experiences. Retrieved from NCSU Institutional Repository, NC State Theses and Dissertations: http://www.lib.ncsu.edu/resolver/1840.16/1400

Pena-Shaff, J., Altman, W., \& Stephenson, H. (2005). Asynchronous online discussions as a tool for learning: Students' attitudes, expectations, and perceptions. Journal of Interactive Learning Research, 16(4), 409-430.

Perna, L. W. (2006). Studying college access and choice: A proposed conceptual model. Higher Education. 21, 99-157

Pittman, L., \& Richmond, A. (2008). University belonging, friendship quality, and psychological adjustment during the transition to college. The Journal of Experimental Education, 76(4), 343-362.

Potts, D. (2015). Understanding the early career benefits of learning abroad programs. Journal of Studies in International Education, 19(5), 441-459.

Redden, E. (2014). Generation study abroad. Inside Higher Ed. Retrieved from: https://www.insidehighered.com/news/2014/03/03/new-initiative-aims-double-numberamericans-studying-abroad 
Robertson, M., Line, M., Jones, S., \& Thomas, S. (2000). International students, learning environments and perceptions: A case study using the Delphi technique. Higher Education Research \& Development, 19(1), 89-102.

Ruben, B. D., \& Kealey, D. J. (1979). Behavioral assessment of communication competency and the prediction of cross-cultural adaptation. International Journal of Intercultural Relations, 3(1), 15-47.

Sachau, D., Brasher, N., \& Fee, S. (2010). Three models for short-term study abroad. Journal of Management Education, 34(5), 645-670.

Salisbury, M. H., Umbach, P. D., Paulsen, M. B., \& Pascarella, E. T. (2009). Going global: Understanding the choice process of the intent to study abroad. Research in higher education, 50(2), 119-143.

Sawir, E., Marginson, S., Deumert, A., Nyland, C., \& Ramia, G. (2008). Loneliness and international Students: An Australian study. Journal of Studies in International Education, 12(2), 148-180.

Schroeder, A., Minocha, S. \& Schneidert, C. (2010). The strengths, weaknesses, opportunities and threats of using social software in higher and further education teaching and learning. Journal of Computer Assisted Learning, 26(3), 159-174.

Shaftel, J., Shaftel, T., \& Ahluwalia, R. (2007). International educational experience and intercultural competence. International Journal of Business \& Economics, 6(1), 25-34.

Shao, Y., \& Crook, C. (2015). The potential of a mobile group blog to support cultural learning among overseas students. Journal of Studies in International Education, 19(5), 399422.

Smith, J. (1995). Semi-structured interviewing and qualitative analysis. In: J. Smith, R. Harre, \& Van Langenhove (Eds.), Rethinking Methods in Psychology (pp. 9-26). London: Sage.

Sutton, R. C., \& Rubin, D. L. (2004). The GLOSSARI Project: Initial findings from a systemwide research initiative on study abroad learning outcomes. Frontiers: The Interdisciplinary Journal of Study Abroad, 10, 65-82.

Tolmie, A., \& Boyle, J. (2000). Factors influencing the success of computer mediated communication (CMC) environments in university teaching: A review and case study. Computers \& Education, 34(2), 119-140.

Tarrant, M. A. (2010). A conceptual framework for exploring the role of studies abroad in nurturing global citizenship. Journal of Studies in International Education, 14(5), 433-451.

Thirolf, K. Q. (2014). Male college student perceptions of intercultural and study abroad programs. Journal of Student Affairs Research and Practice, 51(3), 246-258. 
Tourangeau, R. (1984). Cognitive sciences and survey methods. In T. Jabine, M. Straf, J. Tanur, R. Tourangeau (Eds.) Cognitive aspects of survey methodology: Building a bridge between disciplines (pp. 73-100). Washington, DC: The National Academies Press.

Williams, T. R. (2005). Exploring the impact of study abroad on students' intercultural communication skills: Adaptability and sensitivity. Journal of Studies in International Education, 9(4), 356-371.

Wright, N. D., \& Clarke, I. (2010). Preparing marketing students for a global and multicultural work environment: The value of a semester-long study abroad program. Marketing Education Review, 20(2), 149-162.

Wright, C., \& Schartner, A. (2013). 'I can't ... I won't?' International students at the threshold of social interaction. Journal of Research in International Education, 12(2), 113-128.

Yueh, H. P., Lin, W., \& Lu, T. (2014). Users' perceptions of blog functions: Educational vs personal use. Program: Electronic Library and Information Systems, 48(1), 41-52.

\section{Author biography}

Dr Robin Bell joined the Worcester Business School, University of Worcester in 2011 and works as a Senior Lecturer within the Marketing subject group, specialising in entrepreneurship and international enterprise. He is the Business School's Director of International Partnerships, responsible for inbound and outbound student and staff mobility, partner collaboration, and the Business School's online degree program. Dr Bell is also currently a Visiting Professor at Beijing Foreign Studies University. 